Article

\title{
Microbiological Confinement of Two Adjacent Water Wells in Lake Karla Basin, Greece
}

\section{Konstantinos Ar. Kormas *, Alexandra Meziti and Theodoti Papadimitriou}

Department of Ichthyology \& Aquatic Environment, School of Agricultural Sciences, University of Thessaly, Volos 384 46, Greece; E-Mails: ameziti@gmail.com (A.M.); dotipap@gmail.com (T.P.)

* Author to whom correspondence should be addressed; E-Mail: kkormas@uth.gr; Tel.: +30-242-109-3082; Fax: +30-242-109-3157.

Academic Editor: Robin Slawson

Received: 8 September 2015 / Accepted: 26 September 2015 / Published: 30 September 2015

\begin{abstract}
We analyzed the bacterial and archaeal community structure of two adjacent irrigation well waters of the Lake Karla Basin, Central Greece, in order to elucidate their connectivity or confinement by using 454 tag pyrosequencing of the 16S rRNA genes. Although considerable overlap was found at the phylum/high taxonomic level, and also at the operational taxonomic units (OTU) level, the dominant, and most likely active, prokaryotes represented by these OTUs were very different between the two wells. As expected, we found higher bacterial species richness compared to that of archaeal, and this renders Bacteria better for the study of connectivity or confinement of water wells. Some of the taxonomic groups found are amongst those found typically in the terrestrial subsurface and also those that have been recently described, enhancing the importance of the subsurface for expanding our knowledge on microbial diversity. The majority of the archaeal and several of the bacterial OTUs, including the most dominant ones in each well, were related to marine or saline environments, indicating the previously suggested persistence of fertilizer residuals in the basin's soils.
\end{abstract}

Keywords: bacteria; archaea; terrestrial subsurface; water 


\section{Introduction}

Agricultural areas need water for irrigation and one source is lakes and reservoirs, but also groundwater wells. This is one the reasons that in Eastern Central Greece, a part ( $c a .38 \mathrm{~km}^{2}$ surface area) of the former ( $c a .180 \mathrm{~km}^{2}$ surface area) Lake Karla has been under reconstruction for the past few years after it was anthropogenically dried up in 1962. However, the Lake Karla Basin today, is a typical example of groundwater over-exploitation. It is intensively cultivated with high water demanding crops [1]. Part of the area's irrigation needs is served through an extensive network of pumping wells that cause problems with the basin's water table [2]. It has been estimated that the groundwater level is currently more than $200 \mathrm{~m}$ below the land surface at the southern extent of the basin, and the head losses within zones with the most intensive pumping have reached up to $80 \mathrm{~m}$ during the last 20 years [3]. This extended network of pumping wells from the same aquifer provides an excellent field for testing connectivity $v s$. confinement in the terrestrial subsurface waters.

Groundwater habitats are known to host immense numbers of prokaryotes compared to surface waters, yet with much lower metabolic activity mostly due to shortage of energy substrates. Although these systems do not show significant temporal variation, their spatial diversity can be important, reflecting differences in available substrates [4]. To date, there are no taxonomic groups that could be considered as typical for undisturbed groundwater systems [4,5]. On the other hand, microbial community characteristics provide more insights into ecosystem confinement, functionality, and even health. For example, in the marine environment, some biodiversity features of marine bacteria, such as species distribution and community structure, have been proposed as indicators of marine health status [6]. Likewise, Meziti et al. [7] used bacterioplankton community temporal and spatial variability in a semi-enclosed system in order to elucidate impacts from freshwater inputs from the land or a near-by sewage treatment plant. Finally, Pachiadaki and Kormas [8] used co-occurrence of bacterial and archaeal phylotypes in distant methane seeps for depicting isolation vs. inter-connectivity of these deep-sea benthic habitats.

Based on cross-ecosystem investigations, it has been shown that the higher phylogenetic dissimilarities occur between different habitat types than within them, and this is more obvious for subsurface habitats [9]. For instance, deep water and subsurface ecosystems are considered to be relatively stable with the spatial and temporal variation of their microbial communities governed not only by geophysical features but also by hydrochemical and biotic factors [10,11]. Based on these considerations, in this paper, we hypothesized that if two adjacent water wells are connected, then more than $10 \%$ [12] of their prokaryotic community structure would be similar. We used bacterial and archaeal community structure to provide evidence for the confinement or connectivity of two adjacent water wells used for irrigation purposes in the Lake Karla Basin, Greece.

\section{Materials and Methods}

\subsection{Sampling}

Water from two adjacent water wells, named KSL (39 27'13.96" N, 22 45'07.15" E) and KSP $\left(39^{\circ} 26^{\prime} 39.92^{\prime \prime} \mathrm{N}, 22^{\circ} 44^{\prime} 54.93^{\prime \prime}\right.$ E) from the Lake Karla Basin, Central Greece, was collected on 15 September 2011. The depth of the wells, which are $1096 \mathrm{~m}$ apart, was 68 and $162 \mathrm{~m}$ below surface 
(mbs) for KSL and KSP, respectively (Figure S1). The basic abiotic parameters of the two wells along with the prokaryotic abundance of their waters indicates they are very similar environmental settings (Table S1). From each well, the water was collected in sterile $10 \mathrm{~L}$ carboys after letting the water flow at its maximum speed for $10 \mathrm{~min}$. Each carboy was kept in darkness and chilled in a foam box and was transferred to the laboratory within $3 \mathrm{~h}$. Approximately $9 \mathrm{~L}$ from each well were pre-screened through a $180 \mu \mathrm{m}$ nylon filter (Millipore, Billerica, MA, USA). The filtrate was filtered through a $0.2 \mu \mathrm{m}$ isopore polycarbonate filter (Sartorius, Göttingen, Germany) and stored immediately at $-80{ }^{\circ} \mathrm{C}$ until further analysis.

\subsection{Molecular Analysis}

The stored filters were aseptically sliced and their bulk DNA was extracted using the PowerSoil DNA isolation kit (MoBio Laboratories, Carlsbad, CA, USA) according to the manufacturer's protocol. DNA concentrations ranged from 6.2 to $16.1 \mathrm{ng} \cdot \mu \mathrm{L}^{-1}$. The $16 \mathrm{~S}$ rRNA genes were amplified with bacterial primers 27f (AGRGTTTGATCMTGGCTCAG) and 519r (5'-GTNTTACNGCGGCKGCTG-3') and with archaeal primers 349f (5'-GYGCASCAGKCGMGAAW-3') and 915r (5'-GTGCTCCCCCGCCAATTCCT-3'). Sequencing was performed at the sequencing facilities of MRDNA Ltd. (Shallowater, TX, USA). Amplicon pyrosequencing (bTEFAP) was performed as described in Dowd et al. [13]. In brief, a one-step 30-cycle polymerase chain reaction (PCR) reaction was applied using HotStarTaq Plus Master Mix Kit (Qiagen, Valencia, CA, USA). PCR conditions included: $94{ }^{\circ} \mathrm{C}$ for $3 \mathrm{~min}$, followed by 28 cycles of $94{ }^{\circ} \mathrm{C}$ for $30 \mathrm{~s} ; 53{ }^{\circ} \mathrm{C}$ for $40 \mathrm{~s}$ and $72{ }^{\circ} \mathrm{C}$ for $1 \mathrm{~min}$; and a final elongation step at $72{ }^{\circ} \mathrm{C}$ for $5 \mathrm{~min}$. Following PCR, all amplicon products from different samples were mixed in equal concentrations and purified using Agencourt Ampure beads (Agencourt Bioscience Corporation, MA, USA). Samples were sequenced utilizing Roche 454 FLX Titanium instruments and reagents following the manufacturer's guidelines.

\subsection{Data Processing and Analysis}

Sequence data were analyzed using the software MOTHUR 1.33.0 [14]. Flowgrams from each sample were separated based on their tag and then denoised using PyroNoise software [15]. After removing primer sequences, TAG, and key fragments, only sequences with $\geq 200 \mathrm{bp}$ with homopolymers $<8$ bp were considered for further analysis. Chimeric sequences were removed using UCHIME [16]. Clustering of the remaining sequences was based on a 97\% similarity cut-off limit. Singletons, i.e., sequences that occurred only once in the whole dataset, were removed from further analysis, as they are likely to be sequencing artifacts [17,18]. Taxonomic affiliation was assigned according to the SILVA 111 SSU RNA database [19]. Sequences from this study have been submitted to the GenBank Short Reads Archive (accession number SRX1181212).

\section{Results and Discussion}

We used 16S rRNA gene tag pyrosequencing to reveal the bacterial and archaeal community structure of two adjacent water wells as a proxy for determining the wells' degree of connectivity or confinement. We hypothesized that if the wells were connected, the circulating water in those wells 
would harbor microbial communities of similar phylogenetic diversity and structure. Rarefaction analysis showed our sequencing efforts reached a plateau (Figure 1), indicating that our analysis revealed the majority of the species richness present, i.e., operational taxonomic units (OTUs), for both the Bacteria and the Archaea. This was also depicted in terms of sample coverage (Table 1), which exceeded $91.8 \%$ for both samples and both domains of life. This shows the 454 pyrosequencing method was able to satisfactorily reveal the species richness of these aquifers [20] compared to earlier 16S rRNA gene clone libraries and sequencing [21].

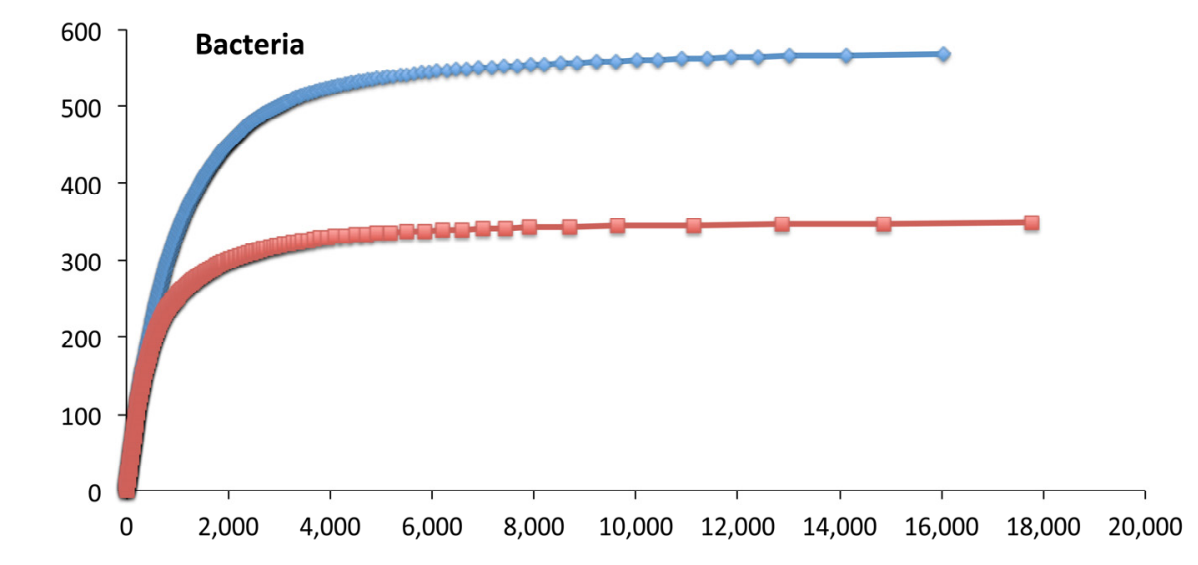

$\stackrel{n}{5}$

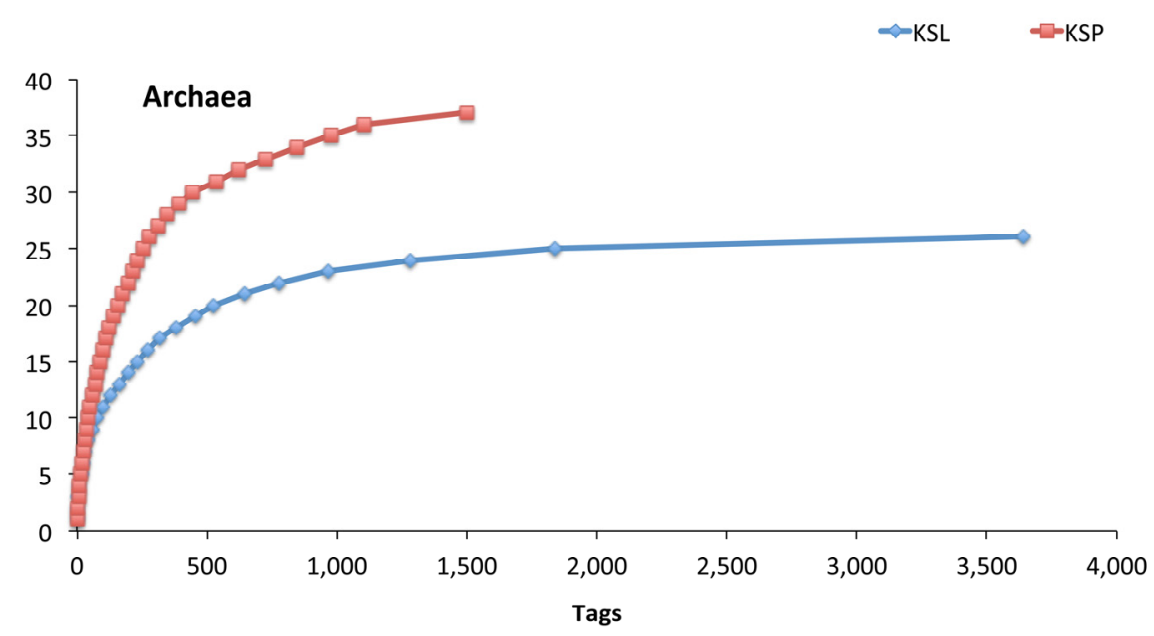

Figure 1. Rarefaction curves of the operational taxonomic units (OTUs) in two water wells (KSL and KSP) of the Lake Karla Basin, Greece.

Table 1. Pyrosequencing results of the 16S rRNA gene in two water wells (KSL and KSP) of the Lake Karla Basin, Greece. OTUs: operational taxonomic units.

\begin{tabular}{cccccc}
\hline Sample & Reads & OTUs & $\begin{array}{c}\text { Coverage } \\
\text { (Schao) }\end{array}$ & $\begin{array}{c}\text { Dominance of the Most } \\
\text { Abundant OTU }\end{array}$ & $\begin{array}{c}\text { No. of Most Dominant OTUs } \\
\text { (Cumulative Relative Dominance) }\end{array}$ \\
\hline KSL & 16,529 & 568 & $91.8 \%$ & Bacteria & $29(66.0 \%)$ \\
KSP & 18,056 & 348 & $92.6 \%$ & $11.7 \%$ & $11(66.0 \%)$ \\
\hline KSL & 3,637 & 25 & $99.4 \%$ & Archaea & $3(73.4 \%)$ \\
KSP & 1,500 & 36 & $93.9 \%$ & $49.5 \%$ & $8(73.9 \%)$ \\
\hline
\end{tabular}


Bacterial OTU numbers were $c a .23$ and 10 times higher compared to those of the Archaea for KSL and KSP, respectively. It has been shown, for a variety of aquatic environments, that archaeal communities have lower species complexity compared to the Bacteria [22], possibly due to the constant environmental stress the Archaea face [23]. The first evidence for possible connectivity between the two wells arises from their similar fundamental abiotic and biotic features (Table S1). The high percentage of shared (common) OTUs between the two wells may support this notion (Figure 2). The two wells share $15.4 \%$ of the 794 unique bacterial OTUs but $34.4 \%$ of the 40 unique archaeal OTUs. Although no globally accepted threshold of shared OTUs between two habitats exists that defines connectivity $v s$. isolation, it has been suggested that when habitats have $<10 \%$ of shared bacterial types, then they are considered rather distinct, i.e., isolated from each other [12]. Shabarova and Pernthaler [24] reported only one common OTU out of a total of 150 OTUs in three subsurface pools of the same karst cave system. Taking into account the proximity of the two wells, the rather high percentage of shared OTUs may indicate close connection between them, and/or similar dominant environmental parameters.
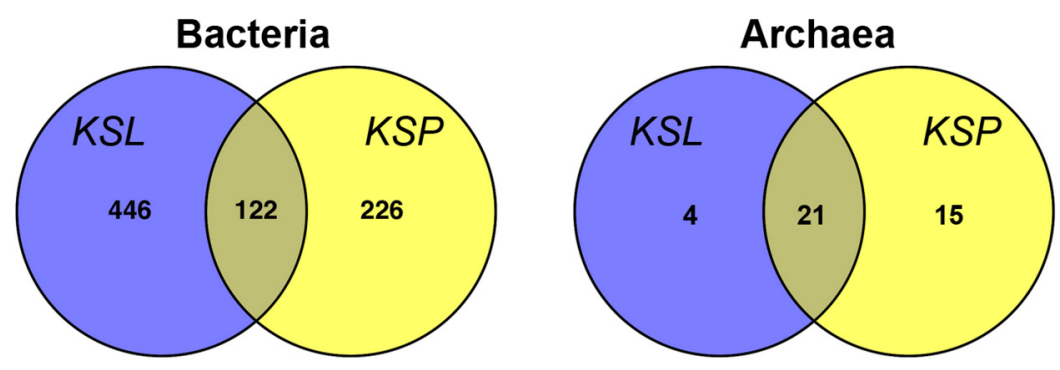

Figure 2. Venn diagrams of the shared and unique bacterial and archaeal operational taxonomic units in two water wells (KSL and KSP) of the Lake Karla Basin, Greece.

The next evidence for possible connectivity between the two wells comes from the community structure at the two sites. Regarding Bacteria, the 794 OTUs belonged to 31 higher taxonomic groups, with 24 of these groups being found in both wells. However, the relative abundance of these taxa was different in the two wells. The five most abundant taxa (Figure 3) for KSL were the Candidatus Saccharibacteria (15.5\%), Verrucomicrobia (12.0\%), Gracilibacteria (7.8\%), Actinobacteria (6.5\%) and Chlamydiae (5.9\%), while the five most dominant taxa for KSP were the Planctomycetes (32.4\%), Verrucomicrobia (8.3\%), Latescibacteria (7.9\%), Acidobacteria (6.6\%) and Candidatus Saccharibacteria (6.3\%). Members of these groups have been detected previously in subsurface habitats $[5,25,26]$, reflecting the subsurface character of our samples. All archaeal OTUs belonged to the Euryarchaeota, Crenarchaeota or were unaffiliated. Due perhaps to the small number of archaeal OTUs detected, no obvious differences in the relative abundance of the higher archaeal taxa were observed (Figure 3). Although community structural diversity does not necessarily imply functional diversity [27], the differences in the dominant phyla (Figure 3) suggest that the ecophysiological roles of these dominant Bacteria (Table S2) are different in the two wells. 

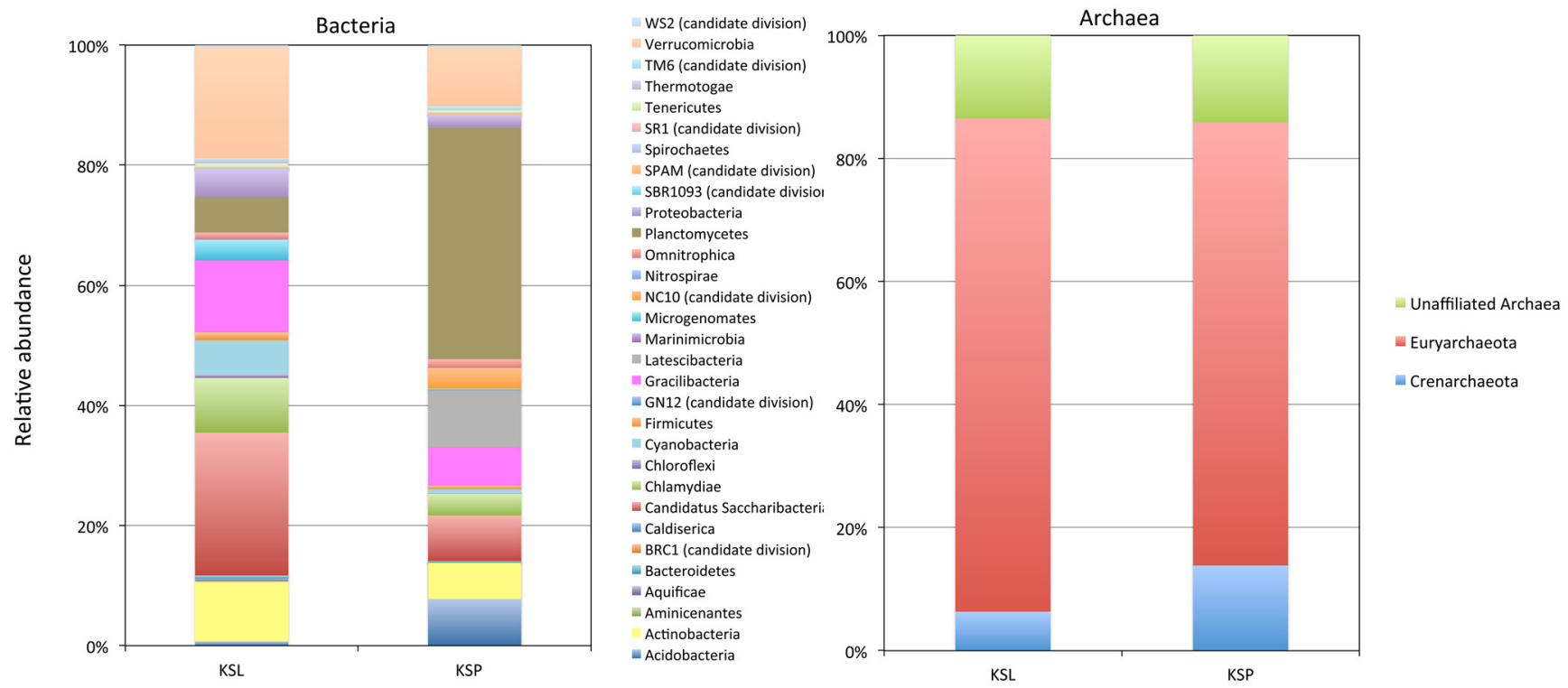

Figure 3. Proportions of the bacterial and archaeal phyla and high taxonomic groups found in two water wells (KSL and KSP) of the Lake Karla Basin, Greece.

Difference between the microbial communities is also evident at the level of the 97\% OTUs. Although the two wells share 31 of 35 bacterial OTUs with $>1 \%$ relative abundance (Figure 4 ), the relative abundance of these OTUs is also very different between them. For example, the most dominant OTU in KSL was B-001 (11.7\%) while in KSP it was B-012 (16.0\%). In microbial communities, the dominant species most likely occupies a fundamental niche in that habitat [28]. In KSL, B-001 is related (Table S2) to the marine obligate oligotrophic ultramicrobacterium Sphingopyxis alaskensis (fam. Sphingomonadaceae) [29,30] while B-012 is closely affiliated (Table S2) to a Rhodobacteraceae Thioclava sp., two bacteria with different cell morphologies, ecophysiological traits and evolutionary histories. The genus Thioclava consists of two marine species, T. dalianensis [31] and T. pacifica [32] both able to oxidize reduced sulfur compounds. A similar pattern was observed for the Archaea (Table S2), despite their much lower species richness. KSL was dominated (49.5\%) by a member of the methanogenic Methanosarcinales, while KSP was dominated $(26.4 \%)$ by a Nitrosopumilus-like OTU. The Nitrosopumilaceae family contains three species, all of which have a marine origin [33-35]. The majority of the archaeal OTUs, along with some of the bacterial ones, including the dominant bacterial OTUs B-001 and B-012, are related to taxa from marine or saline environments (Table S2).

The conductivity of the well waters is rather high (Table S1) and seawater intrusion in the basin area has been proposed [36] due to lowering of the water table. However, Sidiropoulos [37] suggests that the increased salinity in the basin's groundwater is mostly due to leaching of salts from the fertilized agricultural land. It has been shown that nitrogen fertilizers applied to crops can stay in the soil and leach out as nitrate to subsurface waters for several decades following their application [38,39]. The increased salinity of Lake Karla water due to such application of fertilizers for several decades prior to its reconstruction might have led to the occurrence of salt tolerant protists and algae during the first years of the Lake's refilling [40]. 


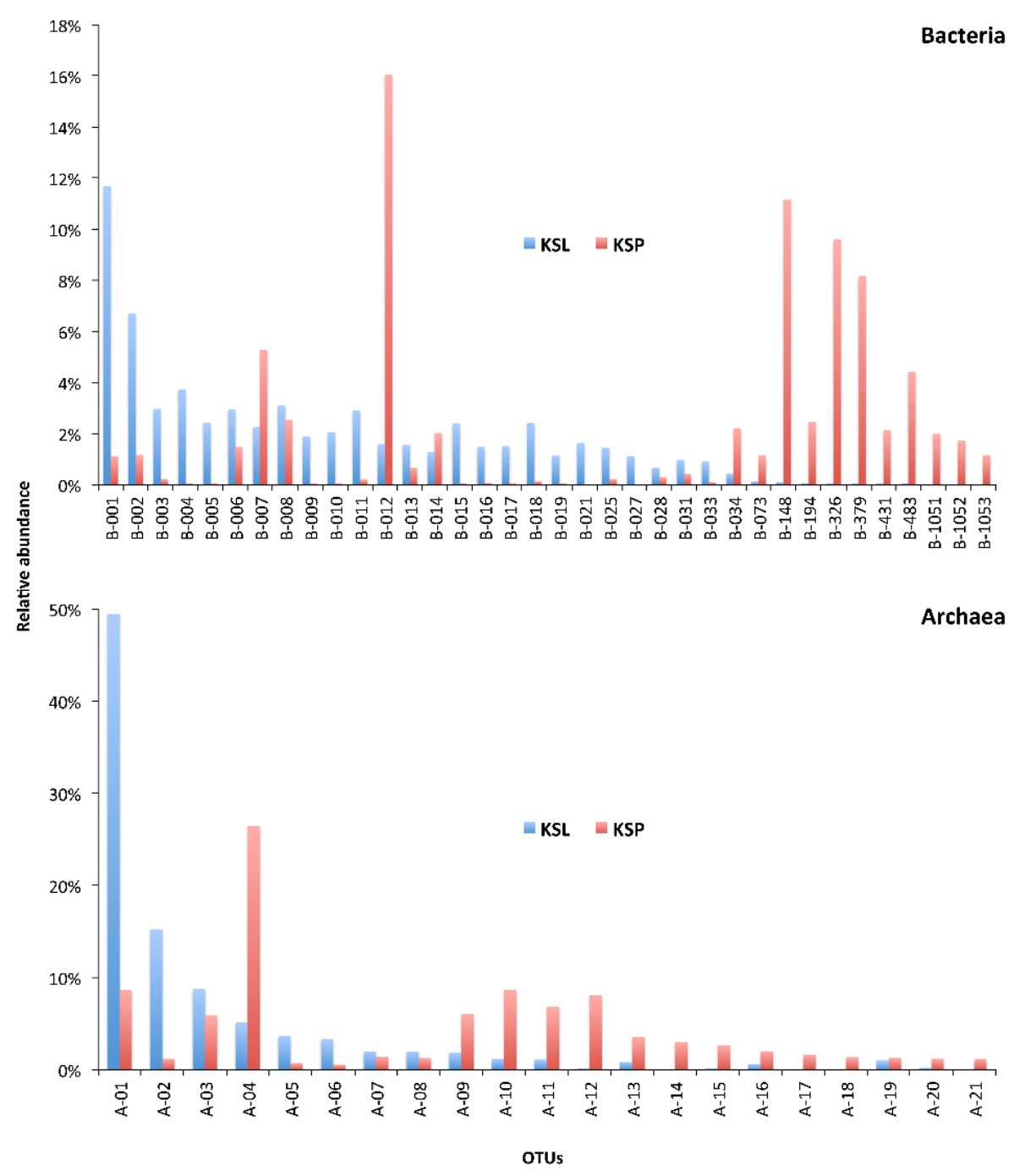

Figure 4. The most dominant bacterial and archaeal (relative abundance $>1 \%$ ) operational taxonomic units (OTUs) in two water wells (KSL and KSP) of the Lake Karla Basin, Greece.

It has been suggested for several years that Earth's terrestrial subsurface biosphere hosts $40 \%-50 \%$ of the world's biomass [41]. Moreover, the microorganisms found in this habitat are frequently novel either at the phylogenetic level and/or their physiological features [42-44]. In this study, we found 31 bacterial phyla or high yet-unaffiliated taxonomic groups. Among these, some have been known previously from subsurface habitats but have only recently been characterized, e.g., Gracilibacteria [45], Candidatus Saccharibacteria [46], Omnitrophica [45], and Microgenomates [45]. Establishment of the taxonomic affiliation of these phyla will enable us to explore their potential ecophysiological role in the subsurface environment. This will require focused and interdisciplinary approaches that fall out of the scope of this paper.

Evidence that the prokaryotic communities in these two wells may be somewhat environmentally/ecologically confined, comes from the rest of the OTUs detected in each well. Subsurface habitats are characterized by high numbers of rare OTUs (sensu $[47,48]$ ) and this was true for the Bacteria in water samples from these two wells. In KSL, the rare bacterial OTUs comprised $66.9 \%$ of the total OTUs while in KSP they comprised 88.2\% (Figure 5). Additionally, less than 5\% of 
the rare OTUs occurred in both wells (data not shown), suggesting that the two wells are located in distinct environmental settings.

Bacteria

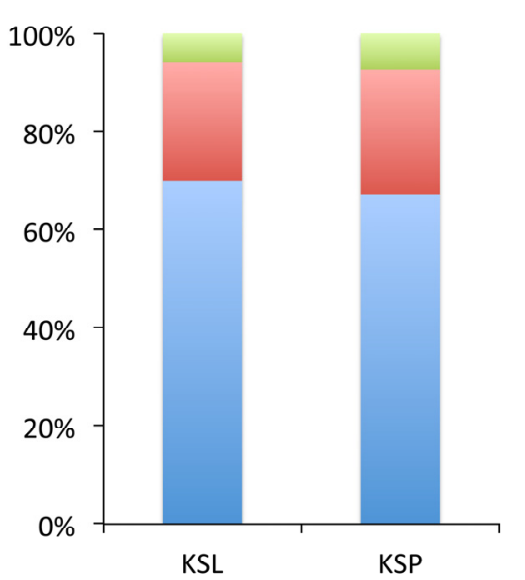

Archaea

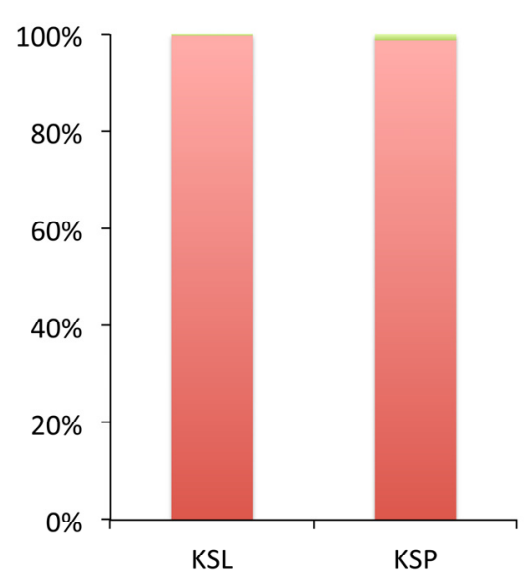

Abundant $(>1 \%)=$ Common $(0.1-1.0 \%) \quad \square$ Rare $(<0.1 \%)$

Figure 5. The percentage of abundant, common and rare bacterial and archaeal operational taxonomic units (OTUs) in two water wells (KSL and KSP) of the Lake Karla Basin, Greece.

\section{Conclusions}

Overall, we showed that adjacent water wells can harbor a high percentage of shared OTUs, however the distribution and structure of their microbial communities shows that these closely-located sites may represent distinct habitats with different environmental conditions. Moreover, the phylogenetic diversity of some OTUs points to long-time persistence of increased salt concentrations at both sites, possibly due to past soil fertilization practices that have led to the occurrence and dominance of some salt-tolerant taxa, mostly Archaea.

\section{Acknowledgments}

The Local Organization of Land Reclamation at Stefanovikeio, Greece, The Management Body of Karla-Mayrovounio-Kefalovriso-Velestino and Pantelis Sidiropoulos are acknowledged for their assistance on sampling. The authors would like to thank Virginia P. Edgcomb, Woods Hole Oceanographic Institution, USA, for her suggestions in improving the English of the text and the three anonymous reviewers for their comments on the paper.

\section{Author Contributions}

Konstantinos Ar. Kormas conceived and designed the study; Konstantinos Ar. Kormas, Theodoti Papadimitriou performed sampling and part of the analysis; Konstantinos Ar. Kormas, Alexandra Meziti, Theodoti Papadimitriou performed molecular analysis, data processing and wrote the paper.

\section{Conflicts of Interest}

The authors declare no conflict of interest. 


\section{References}

1. Zalidis, G.C.; Takavakoglou, V.; Panoras, A.; Bilas, G.; Katsavouni, S. Re-establishing a sustainable wetland at former Lake Karla, Greece, using Ramsar restoration guidelines. Environ. Manag. 2004, 34, 875-886.

2. Sidiropoulos, P.; Mylopoulos, N.; Loukas, A. Optimal management of an overexploited aquifer under climate change: The lake Karla case. Water Resour. Manag. 2013, 27, 1635-1649.

3. Sidiropoulos, P. Simulation and Management of Groundwater Reservoir of Lake Karla with Modflow 2000. Bachelor's Thesis, University of Thessaly, Karditsa, Greece, June, 2004.

4. Griebler, C.; Lueders, T. Microbial biodiversity in groundwater ecosystems. Freshw. Biol. 2009, 54, 649-677.

5. Pernthaler, J. Freshwater microbial communities. In The Prokaryotes; Rosenberg, E., DeLong, E., Lory, S., Stackebrandt, E., Thompson, F., Eds.; Springer: Berlin, Germany, 2013.

6. Bourlat, S.J.; Borja, A.; Gilbert, J.; Taylor, M.I.; Davies, N.; Weisberg, S.B.; Griffith, J.F.; Lettieri, T.; Field, D.; Benzie, J.; et al. Genomics in marine monitoring: New opportunities for assessing marine health status. Marine Pollut. Bull. 2013, 74, 19-31.

7. Meziti, A.; Kormas, K.A.; Moustaka-Gouni, M.; Karayanni, H. Spatially uniform but temporally variable bacterioplankton in a semi-enclosed coastal area. Syst. Appl. Microbiol. 2015, 38, 358-367.

8. Pachiadaki, M.G.; Kormas, K.A. Interconnectivity vs. Isolation of prokaryotic communities in European deep-sea mud volcanoes. Biogeosciences 2013, 10, 2821-2831.

9. Wang, J.; Shen, J.; Wu, Y.; Tu, C.; Soininen, J.; Stegen, J.C.; He, J.; Liu, X.; Zhang, L.; Zhang, E. Phylogenetic beta diversity in bacterial assemblages across ecosystems: Deterministic versus stochastic processes. ISME J. 2013, 7, 1310-1321.

10. Stegen, J.C.; Lin, X.; Konopka, A.E.; Fredrickson, J.K. Stochastic and deterministic assembly processes in subsurface microbial communities. ISME J. 2012, 6, 1653-1664.

11. Lin, W.; Wang, Y.; Gorby, Y.; Nealson, K.; Pan, Y. Integrating niche-based process and spatial process in biogeography of magnetotactic bacteria. Sci. Rep. 2013, 3, doi:10.1038/srep01643.

12. Zinger, L.; Amaral-Zettler, L.A.; Fuhrman, J.A.; Horner-Devine, M.C.; Huse, S.M.; Welch, D.B.M.; Martiny, J.B.H.; Sogin, M.; Boetius, A.; Ramette, A. Global patterns of bacterial beta-diversity in seafloor and seawater ecosystems. PLOS ONE 2011, 6, e24570.

13. Dowd, S.; Callaway, T.; Wolcott, R.; Sun, Y.; McKeehan, T.; Hagevoort, R.; Edrington, T. Evaluation of the bacterial diversity in the feces of cattle using 16s rDNA bacterial tag-encoded FLX amplicon pyrosequencing (bTEFAP). BMC Microbiol. 2008, 8, doi:10.1186/1471-2180-8-125.

14. Schloss, P.D.; Westcott, S.L.; Ryabin, T.; Hall, J.R.; Hartmann, M.; Hollister, E.B.; Lesniewski, R.A.; Oakley, B.B.; Parks, D.H.; Robinson, C.J.; et al. Introducing MOTHUR: Open-source, platform-independent, community-supported software for describing and comparing microbial communities. Appl. Environ. Microbiol. 2009, 75, 7537-7541.

15. Quince, C.; Lanzen, A.; Curtis, T.P.; Davenport, R.J.; Hall, N.; Head, I.M.; Read, L.F.; Sloan, W.T. Accurate determination of microbial diversity from 454 pyrosequencing data. Nat. Meth. 2009, 6, 639-641. 
16. Edgar, R. Search and clustering orders of magnitude faster than blast. Bioinformatics 2010, 26, 2460-2461.

17. Reeder, J.; Knight, R. The rare biosphere: A reality check. Nat. Rev. Microbiol. 2009, 6, 636-637.

18. Kunin, V.; Engelbrektson, A.; Ochman, H.; Hugenholtz, P. Wrinkles in the rare biosphere: Pyrosequencing errors can lead to artificial inflation of diversity estimates. Environ. Microbiol. 2010, 12, 118-123.

19. Pruesse, E.; Quast, C.; Knittel, K.; Fuchs, B.; Ludwig, W.; Peplies, J.; Glöckner, F. Silva: A comprehensive online resource for quality checked and aligned ribosomal RNA sequence data compatible with ARB. Nucleic Acids Res. 2007, 35, 7188-7196.

20. Pilloni, G.; Granitsiotis, M.S.; Engel, M.; Lueders, T. Testing the limits of 454 pyrotag sequencing: Reproducibility, quantitative assessment and comparison to T-RFLP fingerprinting of aquifer microbes. PLoS ONE 2012, 7, e40467.

21. Amann, R.I.; Ludwig, W.; Schleifer, K.H. Phylogenetic identification and in situ detection of individual microbial cells without cultivation. Microbiol. Rev. 1995, 59, 143-169.

22. Smeti, E.; Kormas, K.A.; Spatharis, S. A non-phylogenetic alpha diversity approach on prokaryotic community structure in aquatic systems. Ecol. Indic. 2013, 29, 361-366.

23. Valentine, D.L. Adaptations to energy stress dictate the ecology and evolution of the Archaea. Nat. Rev. Microbiol. 2007, 5, 316-323.

24. Shabarova, T.; Pernthaler, J. Karst pools in subsurface environments: Collectors of microbial diversity or temporary residence between habitat types. Environ. Microbiol. 2010, 12, 1061-1074.

25. Miyoshi, T.; Iwatsuki, T.; Naganuma, T. Phylogenetic characterization of $16 \mathrm{~s}$ rRNA gene clones from deep-groundwater microorganisms that pass through 0.2-micrometer-pore-size filters. Appl. Environ. Microbiol. 2005, 71, 1084-1088.

26. Smith, R.J.; Jeffries, T.C.; Roudnew, B.; Fitch, A.J.; Seymour, J.R.; Delpin, M.W.; Newton, K.; Brown, M.H.; Mitchell, J.G. Metagenomic comparison of microbial communities inhabiting confined and unconfined aquifer ecosystems. Environ. Microbiol. 2012, 14, 240-253.

27. Burke, C.; Steinberg, P.; Rusch, D.; Kjelleberg, S.; Thomas, T. Bacterial community assembly based on functional genes rather than species. Proc. Natl. Acad. Sci. 2011, 108, 14288-14293.

28. Konopka, A. What is microbial community ecology? ISME J. 2009, 3, 1223-1230.

29. Schut, F.; de Vries, E.J.; Gottschal, J.C.; Robertson, B.R.; Harder, W.; Prins, R.A.; Button, D.K. Isolation of typical marine bacteria by dilution culture: Growth, maintenance, and characteristics of isolates under laboratory conditions. Appl. Environ. Microbiol. 1993, 59, 2150-2160.

30. Lauro, F.M.; McDougald, D.; Thomas, T.; Williams, T.J.; Egan, S.; Rice, S.; DeMaere, M.Z.; Ting, L.; Ertan, H.; Johnson, J.; et al. The genomic basis of trophic strategy in marine bacteria. Proc. Natl. Acad. Sci. 2009, 106, 15527-15533.

31. Zhang, R.; Lai, Q.; Wang, W.; Li, S.; Shao, Z. Thioclava dalianensis sp. nov., isolated from surface seawater. Int. J. Syst. Evolut. Microbiol. 2013, 63, 2981-2985.

32. Sorokin, D.Y.; Tourova, T.P.; Spiridonova, E.M.; Rainey, F.A.; Muyzer, G. Thioclava pacifica gen. nov., sp. nov., a novel facultatively autotrophic, marine, sulfur-oxidizing bacterium from a near-shore sulfidic hydrothermal area. Int. J. Syst. Evolut. Microbiol. 2005, 55, 1069-1075. 
33. Könneke, M.; Bernhard, A.E.; de la Torre, J.R.; Walker, C.B.; Waterbury, J.B.; Stahl, D.A. Isolation of an autotrophic ammonia-oxidizing marine archaeon. Nature 2005, 437, 543-546.

34. Mosier, A.C.; Allen, E.E.; Kim, M.; Ferriera, S.; Francis, C.A. Genome sequence of "Candidatus Nitrosopumilus salaria" BD31, an ammonia-oxidizing archaeon from the San Francisco Bay estuary. J. Bacteriol. 2012, 194, 2121-2122.

35. Park, S.-J.; Kim, J.-G.; Jung, M.-Y.; Kim, S.-J.; Cha, I.-T.; Kwon, K.; Lee, J.-H.; Rhee, S.-K. Draft genome sequence of an ammonia-oxidizing archaeon, "Candidatus Nitrosopumilus koreensis" AR1, from marine sediment. J. Bacteriol. 2012, 194, 6940-6941.

36. Mylopoulos, N.; Kolokytha, E.; Loukas, A.; Mylopoulos, Y. Agricultural and water resources development in Thessaly, Greece in the framework of new European union policies. Int. J. River Basin Manag. 2009, 7, 73-89.

37. Sidiropoulos, P. Management of Groundwater Resources under Uncertainty Conditions the Value of Information in Environmentally Degraded Aquifers. Ph.D. Thesis, University of Thessaly, Karditsa, Greece, November 2014.

38. Sebilo, M.; Mayer, B.; Nicolardot, B.; Pinay, G.; Mariotti, A. Long-term fate of nitrate fertilizer in agricultural soils. Proc. Natl. Acad. Sci. 2013, 110, 18185-18189.

39. Worrall, F.; Howden, N.J.K.; Burt, T.P. Evidence for nitrogen accumulation: The total nitrogen budget of the terrestrial biosphere of a lowland agricultural catchment. Biogeochemistry 2015, 123, 411-428.

40. Oikonomou, A.; Katsiapi, M.; Karayanni, H.; Moustaka-Gouni, M.; Kormas, K.A. Plankton microorganisms coinciding with two consecutive mass fish kills in a newly reconstructed lake. Sci. World J.2012, 2012, 504135.

41. Whitman, W.B.; Coleman, D.C.; Wiebe, W.J. Prokaryotes: The unseen majority. Proc. Natl. Acad. Sci. 1998, 95, 6578-6583.

42. Pedersen, K. The deep subterranean biosphere. Earth Sci. Rev. 1993, 34, 243-260.

43. Krumholz, L.R. Microbial communities in the deep subsurface. Hydrogeol. J. 2000, 8, 4-10.

44. Griebler, C.; Avramov, M. Groundwater ecosystem services: A review. Freshw. Sci. 2015, 34, 355-367.

45. Rinke, C.; Schwientek, P.; Sczyrba, A.; Ivanova, N.N.; Anderson, I.J.; Cheng, J.-F.; Darling, A.; Malfatti, S.; Swan, B.K.; Gies, E.A.; et al. Insights into the phylogeny and coding potential of microbial dark matter. Nature 2013, 499, 431-437.

46. Albertsen, M.; Hugenholtz, P.; Skarshewski, A.; Nielsen, K.L.; Tyson, G.W.; Nielsen, P.H. Genome sequences of rare, uncultured bacteria obtained by differential coverage binning of multiple metagenomes. Nat. Biotech. 2013, 31, 533-538.

47. Sogin, M.L.; Morrison, H.G.; Huber, J.A.; Welch, D.M.; Huse, S.M.; Neal, P.R.; Arrieta, J.M.; Herndl, G.J. Microbial diversity in the deep sea and the underexplored "rare biosphere". Proc. Natl. Acad. Sci. USA 2006, 103, 12115-12120.

48. Pedrós-Alió, C. The rare bacterial biosphere. Ann. Rev. Marine Sci. 2012, 4, 449-466.

49. Boone, D.R.; Castenholz, R.W. The Archaea and the Deeply Branching and Phototrophic Bacteria; Springer: Berlin, Germany, 2001. 
50. Brenner, D.J.; Krieg, N.R.; Staley, J.T. The Proteobacteria; Springer: Berilin, Germany, 2001.

51. De Vos, P.; Garrity, G.; Jones, D.; Krieg, N.R.; Ludwig, W.; Rainey, F.A.; Schleifer, K.-H.; Whitman, W.B. The Firmicutes; Springer: Berlin, Germany, 2009.

52. Goodfellow, M.; Kämpfer, P.; Busse, H.-J.; Trujillo, M.E.; Suzuki, K.-I.; Ludwig, W.; Whitman, W.B. The Actinobacteria; Springer: Berlin, Germany, 2012.

53. Rosenberg, E.; DeLong, E.; Lory, S.; Stackebrandt, E.; Thompson, F. The Prokaryotes: Prokaryotic Biology and Symbiotic Associations; Springer: Berlin, Germany, 2013.

54. Rosenberg, E.; DeLong, E.; Lory, S.; Stackebrandt, E.; Thompson, F. The Prokaryotes: Prokaryotic Communities and Ecophysiology; Springer: Berlin, Germany, 2013.

55. Rosenberg, E.; DeLong, E.; Lory, S.; Stackebrandt, E.; Thompson, F. The Prokaryotes: Prokaryotic Physiology and Biochemistry; Springer: Berlin, Germany, 2013.

(C) 2015 by the authors; licensee MDPI, Basel, Switzerland. This article is an open access article distributed under the terms and conditions of the Creative Commons Attribution license (http://creativecommons.org/licenses/by/4.0/). 